\title{
Las humanidades en la educación superior, perspectiva hermenéutica*
}

\author{
The humanities in higher education, a hermeneutic perspective
}

\section{Noé Héctor Esquivel Estrada**}

\section{RESUMEN}

De la mano con las humanidades, hemos de darle seguimiento

Palabras clave:

a un proyecto de educación integral en el que la formación proeducación fesional, los intereses económicos y de producción de bienes no superior, ocupen el lugar central, sino sean un complemento de la formahumanidades, ción humana, individual y socialmente.

universidad,

Uno de los campos fértiles en el que es factible pensar por qué empresa, la necesidad de las humanidades en la educación superior es la rentabilidad universidad. Por eso nos hemos ocupado, en primer término, en reflexionar sobre la universidad (ser y quehacer). Ahí radica la razón por la que afirmamos que la presencia de las humanidades en la universidad es un factor sustantivo en la formación integral de los universitarios.

El tercer apartado nos conecta con la importancia y necesidad de las humanidades en la educación universitaria, contrastándola con la educación centrada en el beneficio económico, empresarial y de mercado (rentabilidad).

\section{SUMMARY}

Hand in hand with the humanities, we must follow up on an integral education project in which professional training, economic interests, and the production of goods do not occupy the central place but complement human training, individually and socially. One of the fertile fields in which it is feasible to think about why

Keywords: higher education, humanities, university, business, profitability

* Parte de este trabajo fue presentado como Conferencia Magistral en el Primer Congreso Internacional: "La tarea de las Humanidades en la Universidad", en octubre de 2020, evento virtual que se organizó y realizó en la Universidad Autónoma del Estado de México.

** Doctor en filosofía por la Universidad Iberoamericana, campus Ciudad de México. Actual Profesor-Investigador en el Instituto de Estudios Sobre la Universidad (IESU), de la Universidad Autónoma del Estado de México. Contacto: noehectoresquivel49@gmail.com 
humanities are needed in higher education is university. For this reason, we have been concerned, in the first place, with reflecting on the university (being and doing). This is why we affirm that the presence of humanities in university is a substantive factor in the integral formation of university students. The third section connects us with the importance and necessity of humanities in university education, contrasting it with education centered on economic, business, and market benefits (profitability). 


\section{Introducción}

El presente trabajo tiene por objetivo exponer algunas reflexiones críticas sobre los siguientes tres asuntos: 1) someter a análisis algunos rubros que atañen a la educación superior; 2) exponer algunas ideas acerca del ser y quehacer de la universidad actual, y 3) fundamentar por qué la necesidad de las humanidades en la universidad. Finalmente, presentaré algunas reflexiones conclusivas que posibiliten abrir horizontes a nuevas interpretaciones.

La perspectiva desde la que abordo esta temática es la filosofía hermenéutica, procedimiento que se perfila a la provocación de reflexiones y preguntas que den lugar a nuevas investigaciones y posibiliten la transformación de la educación universitaria.

\section{1. ¿Qué decir acerca de la educación superior?}

Iniciamos este apartado con algunas preguntas: ¿qué significa pensar la educación? ¿Es posible desvincularla del carácter eficientista y economicista del que se le ha hecho dependiente en la actualidad? ¿Se le puede vincular con la ética? ¿Tiene sentido buscar o proponer valores que la sustenten? Miguel De la Torre, en "Educación y eticidad en tiempos de la eficiencia", nos presenta la educación como un fenómeno eticizador. Esto significa que no es posible pensar lo humano sin educación y sin ética: "La idea de que el problema de lo humano es 'tener que hacerse', que no hay otro modo de 'humanizarse' sino a través de la educación, y que por ello es necesario hablar de una estructura educada del hombre" (2013 85). Si el hombre se hace, se hace educándose. Y la educación necesariamente se sustenta en valores que definen el 'proyecto de humanidad de esa cultura'. En definitiva, dice el autor, "Una interpretación de la educación en este sentido, efectivamente, nada tiene que ver con formar a los individuos, eficientizar sus habilidades productivas, especializar, o incrementar sus competencias laborales, cognitivas, prácticas o de otro tipo" (Id. 86). Si ésta es su orientación actual, entonces debe tomar otra ruta.

En contraparte a los proyectos y expectativas propuestos por algunas instituciones de educación superior, que se perfilan por lineamientos que poco atienden a las necesidades reales de las que debe ocuparse la 
educación, entonces, ¿de qué sirve "formar" "buenos" profesionistas si carecen de los valores que requiere y exige la vida social? Afirma De la Torre: "Si ser hombre es tener que educarse, entonces, la educación es antropogénesis" (Ibíd.) esto quiere decir que el hombre tiene la responsabilidad de construirse a sí mismo no solo como ser individual, sino socialmente. Pues en esta construcción de sí mismo van inherentes los valores que le dan sentido, fortaleza y proyección a su vida.

De lo que inferimos que no solo tenemos la necesidad sino la obligación de pensar la educación de manera distinta a la propuesta eficientista, economicista y comercial que preocupa tanto a algunas universidades hoy: “...por ello es tan importante que la educación no caiga, no pierda esta función y no reduzca sus expectativas a la capacitación para el trabajo y a ser palanca del desarrollo económico" (Id. 88). Junto a esta preocupación, debe hacerse presente su carácter constitutivamente ético.

No es gratuito que las universidades actuales estén cambiando de rumbo y orienten sus programas "educativos" hacia la capacitación y desarrollo de habilidades técnicas que respondan al sistema de organización capitalista. Da la impresión de que éstas quieren adoptar el sistema educativo de los tecnológicos o de la empresa. Por lo que habrá que preguntarse si este modelo no está remplazando la formación humana por una capacitación técnica que depende de las demandas económicas del sistema neoliberal capitalista, lo que provoca que "la calidad de vida" se vea restringida al crecimiento económico, aun cuando sabemos que éste no satisface los requerimientos mínimos de equidad social.

¿Es posible promover la equidad, en la calidad de la educación, de modo que alcance a todos los seres humanos (niños, adolescentes y jóvenes) en edad de estudios? González Casanova comenta al respecto: “Tan extraordinarias metas no pasarían de ser meras ilusiones si no fuera porque corresponden a los ideales más caros del pensamiento humanista, progresista y revolucionario que se desarrolló en el mundo entero en los últimos trecientos años" (2001 63). Sin embargo, esto no quiere decir que actualmente se satisfaga este objetivo, más bien el panorama actual de la educación nos revela lo contrario. A modo de ejemplo mencionaré un criterio, impuesto por el sistema neoliberal, que se defiende y difunde en los programas educativos: 'hay que limitar la educación a la demanda del mercado de trabajo'. 
Este proyecto de comercialización de la educación superior (en el que se han visto envueltas algunas universidades) ha sido apoyado y sostenido por las políticas del Banco Mundial y del sistema neoliberal, con el objetivo claro de ofertar una educación competitiva en el mercado mundial, en el cual difícilmente se podrá encontrar y visualizar aspectos de una formación humanista, democrática, crítica y creativa (¿para qué?); bajo esta tendencia, pronto se impondrá y establecerá que la educación superior (universitaria) sea un complemento esencial de la educación técnica. Esta política también se ve ampliamente favorecida por la reducción del financiamiento por parte del Estado y por la proyección empresarial de algunas universidades. Además, se constata la incapacidad de los gobiernos para financiar la creciente demanda de la educación superior. Esto, posiblemente, obedece a la crisis financiera en la que se encuentra el poder público del Estado.

¿Qué sucede si la universidad decide no seguir esta trayectoria? Nussbaum habla de la tarea apremiante de una reconversión de la educación. "Aquí es donde la educación es crucial: una buena educación puede llevar a los jóvenes a sentir genuina compasión por las necesidades de los demás, y puede conducir a verlos como personas con derechos iguales a los suyos" (2016 11). Educar es educar a la persona. Así, aparece nuevamente la 'utopía' de la educación, que exige la presencia de un pensamiento crítico que haga frente a la situación actual. Además, esta reconversión de la educación superior exige recuperar los valores que provienen, precisamente, de las disciplinas humanísticas. "Tres valores son particularmente cruciales para una ciudadanía democrática decente. El primero es la capacidad socrática de autocrítica y pensamiento crítico acerca de las tradiciones propias de cada uno" (Id. 12) Y, si bien este valor inicia desde la educación temprana, habrá que reforzarlo y consolidarlo en la educación universitaria, que es donde se puede adquirir conciencia plena de nuestras tareas y responsabilidades sociales.

Un segundo valor es la pluralidad, que consiste en la formación de una capacidad que permite reconocer nuestras diferencias de pensamiento, de acción y de ser (y todo lo que esto conlleva), pero nos une en un interés compartido que es el bien común. Sin este auténtico sentido de pluralidad continuarán nuestras divisiones y luchas, producto del individualismo o de intereses de grupos radicales que buscan su beneficio particular. 
El tercer valor corresponde a la imaginación narrativa.

Esto es la capacidad de pensar en lo que podría ser estar en los zapatos de una persona diferente a uno mismo, ser un lector inteligente de la historia de esa persona y comprender las emociones y los deseos y los anhelos que ese alguien podría tener (Id. 15)

Valor que no se obtiene sino mediante las disciplinas humanísticas (la literatura y las artes) que posibilitan la reflexión y la formación. En ese mismo sentido, Chomsky sostiene que la educación universitaria reconoce que "...su objetivo consiste en que el estudiante adquiera la capacidad para inquirir, para crear, para innovar, para desafiar: eso es la educación" (Chomsky d 6).

En razón de ello, Nussbaum pronuncia un discurso crítico dirigido a los Estados que han enfocado sus políticas públicas educativas en la rentabilidad, esto quiere decir: "naciones de personas con formación técnica que no saben cómo criticar la autoridad, útiles creadores de lucro con imaginaciones torpes"' (2016 1) Se vislumbra la crisis en la educación que sobrepasa la formación política democrática; nos referimos a la crisis del ser humano, sin identidad propia, sin capacidad imaginativa y sin valores humanos. Dice la autora:

Si esta tendencia continúa, las naciones de todo el mundo pronto estarán produciendo generaciones de máquinas útiles, en lugar de ciudadanos completos que puedan pensar por sí mismos, criticar la tradición y entender el significado de los sufrimientos y logros de otras personas (Id. 2).

¿Cómo se está instrumentando esa educación basada en la rentabilidad? La autora pone el dedo en la llaga: "Las humanidades y las artes están siendo eliminadas tanto en la educación primaria/secundaria como en la técnica/universitaria, en prácticamente todas las naciones del mundo, vistas por los responsables políticos como adornos inútiles" (Ibíd.). Aquí caben las preguntas: ¿Qué pasa con las universidades? ¿Dónde ha quedado su fuerza de protesta y proposición? Parece que también las políticas de la educación universitaria se han olvidado o se han doblegado ante la fuerza de la rentabilidad. Se han fijado generar y reforzar los programas basados en la "formación" de habilidades técnicas, que rindan frutos a corto plazo. La educación es 
restringida a un instrumento de desarrollo económico; fuera de este objetivo es vista como una inversión inútil.

¿Cuáles son las capacidades que surgen de las humanidades y de las artes, y que son necesarias para el desarrollo de la humanidad? Comenta Nussbaum: "...la capacidad de pensar de manera crítica; la capacidad de trascender las lealtades locales y acercarse a los problemas mundiales como un 'ciudadano del mundo'; y la capacidad de imaginar comprensivamente la situación del otro" (Id. 4). A estas se podría sumar otras que, precisamente, aporten a la formación de la vida humana, social y cósmica.

Giovanna Carvajal, en su artículo: “Educación significa 'educación para la ciudadanía democrática”, ofrece una síntesis de los principales temas abordados por Nussbaum sobre este asunto. Presenta el contraste entre el modelo de educación para el crecimiento económico y el modelo de educación para la ciudadanía democrática, es decir, para una ciudadanía que tiene por objetivo el desarrollo de la vida humana, envuelta en todos los aspectos que la constituyen y que no la restringen a la rentabilidad económica. Para presentarnos el modelo de ciudadanía democrática señala cuáles serían los valores necesarios e indispensables que deben ser atendidos y promovidos en la educación. Sostiene:

Este modelo de educación le asigna valor a: la dignidad humana, la libertad, la igualdad, la justicia social, la comprensión, el respeto, el interés genuino por los demás, la equidad de género, la creatividad, la imaginación empática, la dupla recíproca razón-compasión, la cooperación, el pensamiento crítico (así como la habilidad y el coraje de expresarlo), el sentido de la responsabilidad individual y la curiosidad en el marco del respeto y la comprensión (2013 78).

Valores que han sido excluidos por el modelo de educación económica, en el cual se fomentan otros "valores" que, a decir verdad, podrían ser más bien antivalores, porque no favorecen ni promueven el desarrollo de la vida humana para todos, sino solo para algunos individuos o grupos minoritarios (elites).

El tema de la educación universitaria nos remite a Boaventura de Sousa (2015) que, en el análisis realizado, presenta las siguientes exigencias para la universidad: mirarse a sí misma de manera autocrítica 
y estar dispuesta a reformarse. Universidad que necesita cambiar de rumbo para responder a las exigencias del mundo actual (de una sociedad más humana). Asocia la crisis de la universidad a un factor que daña su autonomía científica y pedagógica, y que consiste en su dependencia financiera del Estado. Además, sostengo que otro factor que ha sumido en crisis institucional a la universidad es la falta de credibilidad. La universidad, en razón de su postura "educativa", "formativa", profesionalizante, ha perdido credibilidad. No responde a los desafíos que le demanda la sociedad.

Debemos repensar hacia dónde queremos que se oriente la educación superior, cuáles son sus objetivos y de qué manera podemos conjuntar los elementos que la constituyen como educación. González Casanova sostiene que: "vincular el conocimiento científico y técnico con el histórico-político y con las armas epistemológicas y técnicas, morales y críticas de una educación humanista universal y de una política democrática incluyente, es el único proyecto que puede asegurar la subsistencia humana" (2001 139). Pensamos que este concepto ideal de educación no se queda atrapado en el marco de educación universitaria, sino que su proyección alcanza el campo de la realización humana, que es hacia donde debería tender todo esfuerzo de educación humanista.

En esta forma de entender la educación universitaria, el diálogo es el recurso humano insustituible; se trata de un diálogo abierto, responsable, respetuoso, crítico, con capacidad de escucha y habla, es decir, un diálogo transformador de la vida, en el que 'científicos' y 'humanistas' tengan un lenguaje común, una cultura común, que los lleve a 'crear' o 'conformar' una sociedad en la que se pueda convivir en armonía, justicia, equidad y responsabilidad compartida. Compromiso que también se le pediría a la comunidad universitaria, en diálogo consigo misma y con la sociedad.

González Casanova nos propone las siguientes conclusiones:

“* No a la universidad elitista y no al país para unos cuantos.

* No al Estado populista y no a la universidad de masas.

* Sí al país-universidad y a la democracia de las mayorías que aprenden a aprender, a enseñar y a practicar las ciencias y las humanidades en sus propias colectividades, sus aulas y sus redes" (Id. 144). 


\section{Pensemos la universidad Actual}

¿Cuál es el interés que manifiesta la universidad hoy, al pronunciarse por una 'mejora en la calidad de la educación' y hacerla más competitiva? ¿Qué significa la competitividad en la educación? ¿Es posible que el concepto de formación universitaria pueda restringirse a la competencia profesional? ¿Qué requiere la sociedad de los egresados de la universidad: mejores profesionales o, más bien, seres humanos más justos, más sensibles a las necesidades que enfrentamos cotidianamente? ¿Por qué la universidad permite verse exigida y presionada por algunas instituciones y demandas extrañas a su ser y misión? Estas y muchas preguntas más deberían ser pensadas al interior de la universidad. Felipe Vergara Garay, en su trabajo: "Dilema de la universidad actual: negocio o servicio", nos alerta con sus reflexiones acerca de las directrices de la universidad: “...las reformas universitarias que hoy en día están en curso, impulsadas y patrocinadas por diversos organismos internacionales, entre los que destaca la Organización para la Cooperación y el Desarrollo Económicos (OCDE), el Banco Mundial (BM) [están] imponiendo a los gobiernos la orientación a sus políticas educativas, con intenciones privatizadoras" (Vergara Garay 240)ํ․․

Repensar los orígenes de la universidad no es una decisión que quede al arbitrio personal o institucional, es una obligación impostergable para los que no desean fincarse, arraigarse o establecerse en esos orígenes, sino que se empeñan en proponer rutas nuevas, acordes a las exigencias de la vida contemporánea, a fin de darle sentido al ser y quehacer de la universidad actual.

La universidad nace como institución que convoca y congrega a los intelectuales de las diversas disciplinas, con la intención y preocupación de orientar los destinos de la humanidad. El conocimiento sin este impulso vital carece de razón. El saber es saber para ser y hacer. Y el ser debe estar respaldado en el saber, que es un saber para la vida. Por eso la universidad nace con el compromiso de transmitir su ser, su saber y sus conocimientos a los estudiantes y a la sociedad en general, con miras a darle un sentido más humano a la vida. Parece que en estas actividades podría conjuntarse su misión.

1 Advertimos que el tema central de este trabajo no es la privatización de la educación, aunque en algunos momentos se hace mención de ella. 
El profesor Carlos de la Isla, en su escrito "La universidad: conciencia crítica", haciendo alusión al título de su trabajo, se pregunta críticamente: $i$ a cuál universidad nos referimos cuando hablamos de su misión? Pues, muchas universidades en el mundo coinciden solo en el nombre. El título de "universidad" no les conviene esencialmente debido a las actividades y funciones que desempeñan. El autor señala que hay un elemento común que debería identificar a la verdadera universidad, dice:

La Universidad, conciencia crítica de la sociedad, significa que la misión de la Universidad es pensar (la investigación no es otra cosa que pensar al mundo y a nosotros en el mundo), enseñar a pensar (y ésta es la esencia de la educación universitaria), transmitir y acrecentar el pensamiento (en esto consiste la extensión de la cultura) (De la Isla 2).

Renunciar al pensar es un acto de irracionalidad. Por eso, "...son promotoras de la irracionalidad las universidades que se someten al poder político, y son cómplices cuando callan. La Universidad debe conservar siempre su independencia, autonomía y libertad para juzgar; denunciar, anunciar e inventar para preservar la independencia y la libertad de la sociedad" (Ibíd.). Esta es su misión social.

Además, hoy en el mundo nos urge, de manera preocupante y apremiante, la reflexión ética, que no puede estar ausente de la vida universitaria. De la Isla cuestiona: “ ¿qué puede, qué debe decir la Universidad sobre la dimensión ética donde cada quien se apropia el criterio de bondad, de virtud e infalibilidad o donde, por beneficio de los que manejan el provecho del poder, se niegan la validez y la existencia de toda norma ética?" (Id.3). ¿Acaso no constituye esta situación un reto para nuestra racionalidad? Pero, si la universidad ha perdido su autoridad moral en el ejercicio de este enjuiciamiento, entonces ¿cómo reconocer su presencia en la vida social? Y ¿ cómo reconocerla como universidad? Su reto es convenir que le corresponde abrir caminos de luz, esperanza y justicia en un mundo polarizado y dividido, en un mundo de oscuridades generadas por la irracionalidad de la razón.

Es paradójico que algunos pensadores actuales no asuman una actitud crítica ante las diversas visiones opuestas acerca de la universidad contemporánea. Algunos la ven como una empresa sostenida por el 
mercado capitalista, en la que sus profesores son proletarizados y sus estudiantes se convierten en consumidores de servicios. Esta forma de concebir la universidad se convierte en una amenaza, tanto por parte de algunos de sus propios miembros internamente como por parte de algunos factores externos. Al interior, por aquellos que no desean ni permiten que la universidad sea autocrítica; al exterior, por los que han centrado su interés en los beneficios políticos y económicos (ajenos a la universidad). En cambio, otros la piensan como una institución generadora de conocimiento y educación, como un espacio público donde se da lugar al debate abierto y crítico de las ideas. Pero, para quienes no la ven así, el conocimiento, la creatividad y el pensamiento libre empiezan a ser sospechosos y marginados, por carecer de valor económico. Aquí se ubica la postura crítica de Boaventura de Sousa Santos.

Para quienes tenemos interés en la universidad y laboramos en ella, pensamos y sostenemos que la universidad es un bien público necesario, por ser una institución que debe promover el debate abierto y crítico de las ideas. Precisamente, es este ejercicio el que la hace temeraria para los que desean verla como una institución estática y sin involucrarse en los problemas sociales, económicos y políticos.

Un pequeño escrito de José Revueltas, intitulado "Autogestión académica y universidad crítica”, nos muestra dos conceptos íntimamente vinculados que conforman y construyen a la verdadera universidad, es decir, a la universidad crítica con autogestión académica. Ambos términos hacen que ella sea 'conciencia nacional del país' con 'aspiraciones a la libertad, a la democracia y la cultura'.

Así lo ratifica el autor:

La universidad crítica es una conciencia colectiva, pero además es una conciencia de la cultura (en su sentido más amplio) que ha de asumirse en sus dos aspectos: como conocimiento y como transformación (esto es, precisamente, como crítica) de la reali$\operatorname{dad}(2008158)^{2}$.

2 Se presume (por una carta) que es el texto de una conferencia, dictada el 8 de junio de 1971 en el auditorio Che Guevara de la Facultad de Filosofía y Letras de la Universidad Nacional Autónoma de México (UNAM). Aportes del pensamiento crítico latinoamericano (1968: a 40 años del movimiento estudiantil en México). 
Sin ambas características no podemos reconocer a nuestra universidad con capacidad y autoridad moral para pensar a fondo nuestra realidad.

Noam Chomsky, a su vez, en su texto "El trabajo académico, el asalto neoliberal a las universidades y cómo debería ser la educación”, se pregunta ¿cómo pensar en la democratización de la universidad? Sostiene que la democracia en la universidad se expresa de una manera muy sencilla: que todos los integrantes de la comunidad universitaria decidan cómo debe organizarse, legislarse y autogobernarse. Los profesores, los estudiantes y los administrativos deben participar libremente en las funciones sustantivas y adjetivas de la universidad; y no solo en la elección de sus representantes, funcionarios, dirigentes, etcétera. La democracia en la universidad exige reconocer la voz y el voto de cada uno de los sectores que la integran. No hay democracia sin libertad de expresión y decisión. No se trata de reconocer la validez de los órganos o representaciones consultivas, sino de reconocer la capacidad de decisión de cada uno de sus miembros. Por lo tanto, uno de los aspectos fundamentales de la función sustantiva de la universidad es educar para la democracia y la libertad. Aquí el principio de sumisión no tiene cabida.

Paradójicamente, Chomsky apunta que, si la universidad se organiza a la manera de una empresa, entonces es comprensible que comparta los objetivos de la empresa: orden, eficiencia, trabajo precario, personal vulnerable, etcétera, como se lo propone la empresa. Por tal motivo, la universidad no podrá educar mientras no se aparte de la organización empresarial - de negocio-. ¿O educa o es empresa? Los objetivos de educar y ser empresa son excluyentes. Ahí está la paradoja: ¿cómo puede la universidad ser una institución educativa, con objetivos e intereses propios, si su forma de organización e intereses es empresarial? Por eso la tendencia actual, en este mundo globalizado y neoliberal, es la privatización de la educación pública. Si el estudiante quiere o aspira a un título universitario debe pagarlo con sus propios recursos o los de su familia. Y, lo grave es que el Estado parece favorecer y promover esta política como política pública. Si esta tendencia sigue, entonces se puede rescindir a los Estados de sus obligaciones en relación con la educación superior.

Analicemos este pensamiento de Chomsky: 
Sin duda, el dilema entre el financiamiento público y el privado genera a su vez otras contrariedades y dudosos beneficios. Mayor reserva en las investigaciones y sus resultados, amenazas a la independencia y libertad de la actividad académica y la integridad de la institución financiada, la paulatina conversión de la universidad en una corporación supeditada a los criterios de la eficacia que no necesariamente son válidos al interior de la vida universitaria (Chomsky a 3).

Todo ello en detrimento de la educación, que se refleja en los estudiantes, profesores y sociedad en general. Si los intereses son opuestos a la verdadera educación, entonces, ratifica Chomsky: "Generar pensamiento creativo e independiente y creencias críticas y desafiantes, explorar nuevos horizontes y olvidar las restricciones externas. Todo eso es un ideal que sin duda se ha revelado deficiente en la práctica, pero en la medida en que se desarrolló dio cuenta del 'nivel de civilización alcanzado"' (Id. 4). Referente que se convierte en un parámetro para ver el estado de nuestra civilización actual.

Asimismo se pregunta: ¿Por qué preocupa tanto la privatización de la educación en general y, especialmente, la privatización de la educación superior universitaria? Por una razón muy sencilla: la privatización exalta el individualismo y aniquila el interés social. La exaltación del poder privado doblega, somete y obliga a todos a que se le rinda culto. La visión, las necesidades, las carencias y privaciones del otro deben desaparecer. A este poder debe someterse también el Estado, y parece que lo está logrando. Comenta: "El poder privado va por su propio camino, el resto de las personas tienen que subordinarse a él. Bueno, eso es parte del argumento para atacar el sistema de educación pública, que se está extendiendo rápidamente a las universidades" (Chomsky b 1). Juzga que el procedimiento de la privatización atenta contra dos valores éticos que deberían ser resguardados, protegidos y promovidos en la educación, ellos son la solidaridad y la cooperación ${ }^{3}$.

3 Su reiteración sobre las consecuencias para la sociedad civil, en general, acerca de la privatización de la educación se puede consultar en Chomsky, Noam. "El futuro no importa tanto': Chomsky; la privatización de las universidades se preocupa sólo por la ganancia inmediata", Sin embargo (2014), en http://www.sinembargo.mx/20-032014/936862, 2/10. 


\section{3. ¿Por qué las humanidades en la universidad?}

Las siguientes preguntas no tienen otro propósito que "provocar" nuestro pensamiento, con el fin de proponer argumentaciones que sirvan de base para descubrir e impulsar las humanidades como "disciplinas" insustituibles, que posibiliten la formación humana en la educación universitaria ${ }^{4}$. En razón de su fuerza podemos preguntarnos: ¿dónde han quedado las humanidades en la formación del profesional universitario? ¿Qué papel desempeñan en su formación profesional? ¿Se puede pensar en una universidad en la que no estén presentes las humanidades? En el mejor de los casos, parece que su presencia se ha visto limitada al incremento o defensa de una asignatura con contenido 'humanístico'.

Ciertamente, las humanidades son algo y mucho más que una asignatura que trata del ser humano. Porque ser-humano es algo y mucho más que "saber" sobre el ser humano. Este es medularmente el asunto que deseamos abordar en estas reflexiones. Estoy plenamente convencido (así lo confirma la historia de la educación) de que las humanidades se relacionan con la esencia del ser humano, y no solo con el aspecto académico o de conocimiento. El ser humano es algo y mucho más que eso. Si me preguntan qué es ese algo y mucho más, les digo que eso es, precisamente, lo que buscamos indagar aquí y reflexionar sobre ello.

Continuemos con algunas preguntas más: ¿dónde ha quedado el carácter formativo-humano del universitario? ¿Es posible pensar en la universidad sin tomar en cuenta la formación humana del universitario? ¿Es posible que la "formación tecnológica" sustituya la formación humana? ¿Hacia dónde van las humanidades y hacia dónde va la universidad? ¿Será que, por desgracia, nos ha tocado a nosotros pensar y afrontar el futuro de la universidad sin humanidades? ¿Cómo rescatar y promover las humanidades en la universidad, frente a los desafíos e intereses financieros, empresariales, mercantiles o de rentabilidad?

4 No se trata de crear o incrementar algunas asignaturas con contenidos humanos o sociales en todas las áreas de las ciencias que se imparten en la universidad, sino de encontrar y proponer "asignaturas" reflexivo-prácticas que contribuyan al desarrollo humano-educativo del universitario (estudiante y profesor). A manera de ejemplo, podríamos pensar en la ética vinculada con los programas y perfiles de cada una de las disciplinas universitarias. 
Cabe insistir que estos asuntos han sido abordados desde la perspectiva hermenéutica. ¿Por qué? Porque la hermenéutica se encuentra fuertemente ligada a las humanidades (ciencias sociales), en razón de que el tipo de racionalidad que le subyace y la sostiene es la racionalidad dialógica, es decir, se ocupa de asuntos que deben tratarse comunitariamente, a través de la conversación con los otros, a fin de arribar a acuerdos o disensos. En este ejercicio de conversación se "resuelve" el bien, la verdad y otros valores más. Así lo afirma y promueve Gadamer en su obra Verdad y método, procedimiento muy distinto y distante del de las ciencias de la naturaleza $(1984)^{5}$, razón por la que podemos descubrir y afirmar que se trata de una hermenéutica humanista. Precisamente, esta obra la inicia con una detallada exposición sobre los conceptos básicos del humanismo.

Los universitarios y la sociedad tenemos una responsabilidad compartida: a todos nos compete cuidar la vida humana. Es cierto que a la comunidad universitaria le corresponde directamente vigilar que no se entorpezca el estudio de las humanidades. Por ejemplo, cuando en nuestro país la Secretaría de Educación Pública (SEP) intentó hacer desaparecer algunas disciplinas sociales de los currículos de la educación media-superior, ello se juzgó como un atentado contra el espíritu propio de la universidad, contra su autonomía ${ }^{6}=$ capacidad de autoorganización, es decir, de crear sus propios planes y programas de estudio, sus líneas de investigación y métodos de enseñanza, junto con la libertad de cátedra. No se puede continuar elucubrando o promoviendo que la universidad quede al servicio del Estado ni que el objetivo de la universidad hoy sea "formar buenos profesionales", pues su misión consiste en formar buenos seres humanos, lo que incluye también la formación profesional.

De este modo, la enseñanza de las humanidades debería estar presente en toda la universidad, sin perder de vista el campo disciplinario. ¿Qué tienen que ver la matemática, la física, la biología, la química, etcétera, con las humanidades? Ésta es una tarea que atañe pensar y promover propiamente a la universidad (expresión de su autonomía).

5 Tema que también desarrolla ampliamente en esta misma obra.

6 Autonomía que implica las cuatro funciones esenciales de la universidad: autogobernarse, autoorganizarse, autoadministrarse y autolegislarse. 
Si la universidad atiende esta responsabilidad, entonces su actividad formativa se verá reflejada en su comunidad y en la sociedad.

Por eso juzgamos que uno de los grandes retos para la universidad moderna es el estudio y permanencia de las humanidades. Difícilmente podrá desatenderse de esta labor a menos que deje de entenderse o reconocerse como universidad. Rolando Picos, en "La filosofía y las humanidades ante el nuevo ethos universitario", cita un pensamiento de Sánchez Vázquez en el que advierte cuál es el riesgo para la universidad actual, que se ve exigida a cumplir con las demandas de políticas económico-empresariales:

En este mundo en el que el culto supremo se rinde como a nuevos dioses al mercado y al dinero —-señala Sánchez Vázquez-, la filosofía y las humanidades no son rentables, ni productivas. Por eso desaparecen de las universidades privadas empresariales, y se tiende a reducir su presencia en las universidades públicas (2013 219).

Si la universidad no asume una actitud vigilante y expectante de sus propios derroteros, fácilmente quedará atrapada en las redes no solo de las políticas externas y ajenas a su propio espíritu, sino también de "intereses" poco académicos, particulares y antihumanos de sus propios miembros. Rolando Picos así lo advierte:

...la misión de la universidad pública, concebida como un espacio plural y democrático que posibilita la reivindicación de lo humano a partir de la formación de un ethos 'humanístico' en los sujetos, se encuentra en entredicho, cuando no en un franco declive. Las humanidades atraviesan por una severa crisis: hemos pasado rápidamente del humanismo (Lapoujade, 1998) a la competitividad, afectando este nuevo discurso lo que Höffe (2008) llama 'la era de la economización', que implica per se el replanteamiento de la función, orientación y objetivos de la formación universitaria..." (Id. 215).

Considero que es competencia de los universitarios atender esta situación, que no toca cuerdas contingentes o superficiales de la vida y misión de la universidad. No es cosa de menor envergadura, pero, parece que los universitarios seguimos 'adormilados' ante los desatinos de quienes la dirigen y la conformamos. El espíritu crítico del universitario no puede desaparecer o quedar atrapado por las ilusiones de políticas mercantilistas y económicas. La universidad no es una 
empresa que deba responder a los intereses del mercado o del capital económico.

También José Narro, en "Universidad como compromiso social”, se pronuncia a favor de salvaguardar y promover el quehacer de las ciencias sociales en la universidad; no es suficiente con la atención del desarrollo técnico-científico. “También necesitamos de las ciencias sociales, de las humanidades y las artes, porque son fundamentales para el progreso y desarrollo armónico de la colectividad. Es necesario reivindicar la defensa y la promoción de las humanidades y las ciencias sociales" (2016 22). Si bien a partir de la modernidad el conocimiento científico ocupa un lugar relevante al interior de las universidades y de otras instituciones que se ocupan del progreso técnico-científico, no por ello las ciencias humanas deben relegarse o ser suprimidas, cuando sabemos de su importancia y necesidad para la integración de la vida social. Es precisamente a ellas a las que corresponde atender los problemas sociales. Comenta Narro:

No creo faltar a la verdad si digo que a la definición de las políticas públicas para combatir la pobreza y la desigualdad, así como a otras políticas sociales, mucha falta le hace tomar en cuenta los conocimientos que producen nuestros científicos sociales. (...) Las ciencias sociales y humanas son fundamentales para preservar la cultura, por ello, ninguna universidad puede prescindir de ellas"(Id. 23).

Es tarea de todos los universitarios, pero de manera especial de quienes hemos incursionado en el campo de las ciencias humanas, atender los problemas y requerimientos de la vida social, sin desconocer el desarrollo técnico-científico de las ciencias exactas.

Cuando decimos que a la universidad corresponde ocuparse de las humanidades, el peligro se hace inminente si se piensa que las humanidades son un catálogo de asignaturas que se ocupan del hombre; es necesaria su reconversión: ellas se vinculan con nuestro modo de ser y de estar en el mundo, y con el mundo. Somos los seres que nos caracterizamos por este modo de ser y de estar; quizá éste sea nuestro privilegio pero no nuestra superioridad.

El texto de Rafael González: "Martha Nussbaum: humanidades y universidad en el siglo XXI" abre las puertas para abocarnos a dos asuntos que juzgamos relevantes para la educación (desde la perspec- 
tiva de Nussbaum), a saber: 1) el significado del humanismo en el siglo XXI y 2) el papel de las humanidades en la universidad.

La dificultad de abordar el tema del humanismo en la actualidad se manifiesta por la falta de relevancia intelectual de las humanidades y la exorbitante valoración de la "formación" técnica. Con esta misma reflexión, Heidegger piensa que el humanismo no se ha ocupado ni ha dado una respuesta a lo que significa la dignidad auténtica del hombre, se ha olvidado de la pregunta por el ser y se ha ocupado solo de los entes que están a la mano para su dominación. "Esa incomprensión del horizonte último del ser por parte de los hombres les impide reconocerse y entenderse a sí mismos y a la naturaleza" (González Díaz 74).

Así también se enlaza el pensamiento de Derrida, cuando habla de la incondicionalidad de la verdad, tarea de las humanidades, que significa reconocer el derecho de hacer público cuanto proviene de la investigación, del conocimiento y del pensamiento (como propiedad de la verdad misma). Una de las tareas de la universidad consistirá en la resignificación del ser del hombre desde las humanidades, sin condiciones y sin presuposiciones. "Las aportaciones de Heidegger, Derrida y Hannah Arendt hacen patente que la cuestión sobre las humanidades, la educación y la universidad sigue siendo relevante, y que la podemos caracterizar con las siguientes preguntas: ¿qué significado tiene el humanismo en el siglo XXI? ¿Qué papel tienen las humanidades en la universidad? ¿Qué relación tiene la universidad con la sociedad?" (Id. 76). Aspectos que se encuentran vinculados y que no es posible desatender, porque estamos involucrados en esta "aventura" de la educación humana.

En 2012 Martha Nussbaum recibe el premio Príncipe de Asturias de Ciencias Sociales; con ese motivo le hacen una entrevista en la que le formulan la siguiente pregunta: ¿cómo es posible el pensamiento crítico, cuando las humanidades casi han desaparecido del curriculum educativo? Su respuesta la orientó hacia la importancia de que los jóvenes sepan argumentar y defender sus propias ideas, como fruto de un pensamiento crítico. Por eso, anuncia que el objetivo de estas reflexiones es abrir un espacio a la formación humanista para la democracia liberal, que contraste la "formación" técnica acrítica y utilitaria del sistema educativo actual. 
¿En qué consiste la formación humanista para Nussbaum? Sostiene que la educación debe dirigir sus esfuerzos y acciones hacia la consecución de la libertad y de la igualdad desde sí mismas. "De este modo, la educación es planteada como un cultivo de la humanidad, que busca fortalecer las facultades del pensamiento, la emoción y la imaginación que permite a los hombres reconocer su propia humanidad y la de los demás" (Álvarez 29). El punto de partida es la formación en el sí mismo, la individualidad, pero con proyección social, es decir, hacia el bien común. El desarrollo de las capacidades y habilidades técnicas pasan a un segundo plano.

Podemos sintetizar que la propuesta de educación humanista de Nussbaum se sustenta en los siguientes tres aspectos:

...la vida examinada, que brinda a los ciudadanos la capacidad de pensar por sí mismos y no por los dictados de la tradición o la autoridad; la ciudadanía mundial, que busca trascender las afiliaciones nacionales más inmediatas para pensar a la humanidad en términos globales, y la imaginación narrativa que, mediante las artes, busca promover el sentimiento de empatía entre los seres humanos (Id. 38, énfasis mío).

Es interesante descubrir, estudiar y proyectar la relación que establece Nussbaum entre "desarrollo humano" y "ciencias humanas"; en particular, su postura crítica acerca del desarrollo" como proyecto de muchos países, centrado en la economía; de tal modo que un país mide y reconoce su desarrollo con base en el producto interno bruto per capita. En oposición a ello, críticamente asume que la idea del desarrollo de un país radica fundamentalmente en su educación humana, en la cual la cuestión económica es tan solo un aspecto del mismo, y no el más importante. Sostiene: "necesitamos una educación bien fundada en las humanidades para realizar el potencial de las sociedades que luchan por la justicia" (González Díaz 79). El crecimiento económico, sin una distribución justa, no significa de ninguna manera desarrollo. Asevera:

Las humanidades nos proporcionan no sólo conocimientos sobre nosotros mismos y sobre los demás, sino que nos hacen reflexionar sobre la vulnerabilidad humana y la aspiración de todo individuo a la justica... No me parece demasiado atrevido afirmar que el flo- 
recimiento humano requiere el florecimiento de las disciplinas de humanidades (Ibid.).

Insiste, de manera especial, en la literatura y las artes.

Es preocupante esta situación por la que transita la educación superior actual, porque pareciera que se pretende ignorar o desconocer toda la tradición que acompaña a la universidad por un objetivo tan pobre como es el amor al dinero; y lo más delicado es que, con base en ese interés, se instrumentalice al ser humano, de manera irracional se induzca a los jóvenes a perder sus ilusiones e imaginaciones y, finalmente, su educación, en aras del objetivo material representado por el dinero. Por ello, compete a la universidad afrontar los hechos con decisión y firmeza para recuperar los valores humanos que se están perdiendo. Así lo expresa Rafael González: "Una característica de esa cultura educativa es la participación activa de los alumnos en la investigación de los temas, la formulación de preguntas y un espíritu crítico en la indagación" (Id. 86).

La vulnerabilidad de la condición humana puede suscitar una doble consideración excluyente u opuesta. Por una parte, ante una visión sensible, la vulnerabilidad de los seres humanos puede conducir hacia el reconocimiento de sus derechos humanos, en la búsqueda de su protección, igualdad y justicia; por otra, puede dar lugar al abuso del poder y la dominación. Frente a la debilidad del ser humano aparece el ejercicio del poder, aprovechándose de esa condición para someter, sojuzgar y oprimir a esos seres humanos. Ambas condiciones son producto de formas de educación distintas; una la educación para la libertad, la equidad, la justicia y el bien, y otra para la dominación, la rentabilidad y la instrumentalidad. Reconocer esta bipolaridad y superarla es fruto de una sólida formación moral que posibilitará que el ser humano reconozca su propia vulnerabilidad y la de los demás, con ánimo de caminar juntos en la construcción de una ciudadanía igualitaria, justa y democrática. Dice González: “El reconocimiento de esa debilidad nos permite transformarnos en seres sociales y construir una comunidad humana. La propia limitación y finitud puede ser el punto de partida para construir una comunidad interdependiente y respetuosa" (Id.97). El carácter de la vida moral no puede perderse en especulaciones abstractas y carentes de sentido, sino concretarse en la vida práctica, individual y socialmente, es 
decir, la vida moral debe ser un elemento constitutivo de la educación.

En la Introducción del libro Gadamer y las Humanidades I. Ontología, lenguaje y estética, Mariflor Aguilar y María Antonia González, coordinadoras, comentan sobre la necesidad de la formación humana en esta visión y trayectoria del mundo globalizado: "H.-G. Gadamer no pudo quedar exento de tales influencias y con su aguda mirada filosófica observó cómo se planificaba el futuro de la humanidad teniendo como base el orden y la eficiencia, sin tomar en cuenta precisamente aquello que nos hace humanos" (2007 12). Seguramente, lo que nos hace humanos se relaciona con las humanidades en la educación y, consecuentemente, con la universidad.

Chomsky califica a la infiltración de este "orden y eficiencia" en la educación superior como "el asalto neoliberal a las universidades", lo que nos exige reconvertir el sentido de la educación y alejarlo de la idea de empresa, negocio. "Cuando las universidades se convierten en empresas, como ha venido ocurriendo harto sistemáticamente durante la última generación, como parte de un asalto neoliberal general a la población, su modelo de negocio entraña que lo que importa es la línea de base" (Chomsky d 1). Esta línea de base se sostiene en la estructura de trabajador temporal, es decir, sin generación de derechos, modelo que se está instaurando en las universidades. Esta forma de contratación exitosa y sana para las empresas asegura el orden y la eficiencia de las mismas, y en los mismos términos se aplica a las universidades ${ }^{7}$.

Otro de los aspectos denunciados por Chomsky como invasión del neoliberalismo en la universidad es la solidificación y fortaleza de la organización administrativa como un recurso de control para la "empresa universitaria". Habrá que poner atención en este punto. "Pero servirse del trabajo barato - y vulnerable- es una práctica de negocio que se remonta a los inicios mismos de la empresa privada, y los sindicatos nacieron respondiendo a eso" (Id.2). La misma forma de contratación y trabajo se está impulsando en las universidades.

$7 \quad$ En México, las autoridades federales, en sus discursos, mencionan frecuentemente el derrocamiento del neoliberalismo, pero sostienen y fomentan el sistema de contratación empresarial en las mismas universidades (contratación CAF). 
Ciertamente la reflexión filosófica, desde la perspectiva hermenéutica de Gadamer, no solo no puede eludir la pregunta por el sentido del ser, de la existencia, del mundo, de la vida y de todo lo que ello implica, sino que es parte constitutiva del ser, pensar y hacer humanos. Para Gadamer: "Por encima de un orden logrado por la técnica, requerimos de una educación para la tolerancia que nos permita la convivencia ciudadana" (Aguilar R. González V. 12). Por eso, si nuestro núcleo reflexivo se orienta hacia la búsqueda del sentido de nuestro ser, "Éste no lo encontramos ni en el orden ni en la eficiencia, sino en nuestra historia, en aquello que nos llega vía la tradición y que nos permite comprendernos a nosotros mismos." (Id. 13).

Para cerrar este apartado, retomaré el trabajo de María Herlinda Suárez "En defensa de la universidad pública”, en el que se resaltan algunas ideas y reflexiones sobre la situación en la que se encuentran las universidades públicas latinoamericanas y cuál es su futuro. Desde su perspectiva crítica, sitúa a las universidades públicas bajo el yugo del sistema neoliberal:

Sin menoscabo del reconocimiento de que en los distintos países e instituciones privan tradiciones y realidades diversas, la tendencia homogeneizadora ha sido la imposición de los criterios y valores del mercado a las instituciones públicas de educación superior. De ahí que puede decirse que el futuro de la universidad pública fue construido a partir de la lógica de los mercados, nacionales e internacionales, así como del manejo de recursos financieros a partir de la evaluación (2016 242-243).

Los datos que respaldan esta condición de las universidades públicas destacan cuál es la calidad de la educación que se les reconoce socialmente.

Sin embargo, en defensa de la universidad pública, la autora sostiene que esta condición se debe a las políticas públicas del Estado que, a través de sus múltiples medios y mecanismos de operar, difunde que la educación privada es superior a la pública, aun recurriendo a campañas de desprestigio tanto de académicos como de estudiantes que pertenecen a la universidad pública ${ }^{8}$.

8 No está dentro de los objetivos de este trabajo abrir la discusión al campo de la educación pública y la educación privada asunto que, indudablemente, exige conocimien- 


\section{A manera de reflexiones "finales"}

¿Qué universidad necesita o requiere el mundo de hoy? Si pretendemos la configuración de un mundo nuevo, un mundo mejor, un mundo más humanitario, entonces indispensablemente necesitamos también otro tipo educación y de universidad. Una universidad que se pronuncie por una educación más universal, sustentada en los principios de la libertad y de la equidad, que ofrezca las mismas oportunidades para todos los ciudadanos, que ponga su mirada, sus inquietudes y objetivos en la restauración del orden social. Una universidad que se proponga y alcance la educación política y moral de todos los ciudadanos, que no quede atrapada en las redes del sistema neoliberal ni de su instrumentalización comercial. Necesitamos de una universidad capaz de pensarse a sí misma críticamente, que se gobierne a sí misma y que se conforme democráticamente.

Deseo recuperar, no textualmente, dos objetivos que me sirven de reflexión final, que se encuentran en González Casanova y en Martha Nussbaum, y que conjuntan ideas presentes en todo el trabajo, ellos son:

1. La universidad ha de procurar educar al estudiante en el binomio inseparable pensar-hacer, en el cual se conjugan una serie de virtudes y cualidades que se plasman en el orden social, tales como: la responsabilidad, el diálogo, el humanismo, la búsqueda de la verdad, la formación política y moral de todo ciudadano, entre otras.

2. Crear sistemas de enseñanza abiertos con la más alta calidad en las especialidades, en el intercambio cultural, en la promoción social y democrática de la sociedad, con el más alto apoyo en la ciencia y en la tecnología, y con la capacidad de diálogo entre todos sus miembros y con quienes no pertenecen a esa tradición cultural o científica (González Casanova 2001).

Cuando afirmamos que la universidad está en crisis, provocada por la pérdida de sus objetivos, no es más que un reflejo de la crisis que vive y padece nuestro sistema educativo. Da la impresión de

to, rigurosidad, respeto y responsabilidad; más bien, estos dos últimos párrafos fueron recuperados por su referencia a las universidades latinoamericanas; pero, aún ese tema requiere amplitud y consistencia. 
que la conducción de la educación, en todos sus niveles, ha quedado sometida al régimen de la racionalidad instrumental, eficientista y pragmática. Nosotros apostamos por una educación que posibilite y permita al hombre pensar críticamente. La resolución de los desafíos prácticos, inmediatos, materiales y económicos será una consecuencia que se derivará del uso adecuado y correcto de una razón plenamente humana, que sea capaz de juzgarse a sí misma, su cultura, su vida social, política y económica; pero no a la inversa. Sin embargo, se percibe, más bien, que el imperativo en la educación actual es el de la utilidad, la rentabilidad, el negocio. Si lo que el hombre aprende, hace y proyecta no trae consigo utilidad, entonces carece de sentido e importancia. ¿Por qué no revertir este rumbo y pensar que la tarea de educar consiste en aprender a vivir de modo humano?

Al final de este discurso podemos arribar a dos conclusiones, a saber:

$1^{\circ}$. Debemos reflexionar acerca de cuáles serán los resultados que obtendremos si las tendencias de la educación actual continúan. La centralización en la educación técnica y la ausencia de un pensamiento crítico generan 'individuos útiles con imaginaciones torpes'. Una educación basada en la rentabilidad construye una sociedad egoísta e individualista, sin una visión social que posibilite la convivencia equitativa, armónica y se conforme una sociedad más humana.

$2^{\circ}$. Para que la educación cambie de rumbo se necesita indispensablemente de la presencia de las humanidades y las artes, pues de ellas depende, en gran medida, edificar un mundo en el que valga la pena vivir, donde la conformación de las personas sea posible sobre la base de su interrelación respetuosa y de ayuda mutua. Se trataría de una sociedad plural, democrática, en diálogo permanente sobre sus problemas, intereses y necesidades comunes.

Así, pues, es indispensable, para la reflexión y orientación de la educación superior, recuperar los pensamientos y preocupaciones externados por algunos intelectuales que laboran en el campo universitario, no echarlos en 'saco roto' con el fin de transformarnos y transformar nuestras instituciones educativas. 


\section{Bibliografía}

Aguilar, M. y González, M. A. Gadamer y las Humanidades I. Ontología, lenguaje y estética. Coordinadoras. México: UNAM, 2007.

Álvarez, Sebastián. "Martha Nussbaum y la educación en humanidades”, Analecta Política 6/10, (2016): 167-178. DOI: http:// dx.doi.org/10.18566/apolit.v6n10.a09

Carvajal Barrios, Giovanna. “Educación significa: 'educación para la ciudadanía democrática”, Miradas 11 (2013): 74-93.

Cordua, Carla. "La crisis de las humanidades", Revista de Filosofía 68 (2012).

Chomsky, Noam. (a) “¿Universidades públicas o privadas?” 3-4, en http://eltoque.com/texto/noam-chomsky-universidadespublicas-o-privadas.. (consultado en agosto 2020).

Chomsky, Noam. (b) "Asaltando la solidaridad: privatizando la educación" 1/4, en http://www.redeseducacion.net/chomsky.htm pp.

Chomsky, Noam. (c) “El futuro no importa tanto': Chomsky; la privatización de las universidades se preocupa sólo por la ganancia inmediata", Sin embargo (2014), en http://www.sinembargo. $\mathrm{mx} / 20-03-2014 / 936862,2 / 10$.

Chomsky, Noam. (d) "El trabajo académico, el asalto neoliberal a las universidades y cómo debería ser la educación”, en http:// sociologos.com/2014/03/13/noam-chomsky-el-trabajoacademico-el-asalto-neoliberal-a-las-universidades-y-como-deberia-ser-la-educacion/ 1/8.

De la Isla, Carlos. "La universidad: conciencia crítica 1/6", en http:// biblioteca.itam.mx/estudios/estudio/letras25/texto4/sec_1html. (Consultado septiembre de 2020).

De Sousa Santos, Boaventura. La universidad en el siglo XXI. México: Siglo XXI Editores, 2015.

De la Torre, Miguel. "Educación y eticidad en tiempos de la eficiencia”. Los bordes de la filosofía. Educación, humanidades y universidad. Xolocotzi, Ángel y Mateos, José Antonio, coordinadores, México: BUAP/Itaca, 2013. 85-96.

Derek, Bok. Universidades a la venta. La comercialización de la educación superior. Valencia: Universitat de Valencia, 2010.

Esquivel E. y Noé H. "Universidad Educativa”, Universitas $N^{\circ} 23$. Reflexiones universitarias V. Parent J., Juan María y Esquivel Es- 
trada, Noé Héctor et al. México: Universidad Autónoma del Estado de México, 1998. 21-23.

“¿Qué destino le espera a las ciencias humanas bajo el dominio de un mundo técnico?”, Universitas $N^{\circ} 23$. Reflexiones universitarias $V$. Parent J., Juan María y Esquivel Estrada, Noé Héctor et al. México: Universidad Autónoma del Estado de México, 1998. 56-59.

“Crisis en la investigación”, 74-79. Universitas $N^{\circ}$ 23. Reflexiones universitarias $V$. Parent J., Juan María y Esquivel Estrada, Noé Héctor et al. México: Universidad Autónoma del Estado de México, 1998.

Gadamer, Hans-Georg. Verdad y método. Fundamentos para una hermenéutica filosófica. Salamanca: Sígueme, 1984.

González C., Pablo. La universidad necesaria en el siglo XXI. México: Ed. Era, 2001.

González D., Rafael. "Martha Nussbaum: humanidades y universidad en el siglo XXI", Estudios XII/110 (2014). ITAM.

Muñoz García, Humberto, coorddinador. ¿Hacia dónde va la universidad en el siglo XXI? México: UNAM/MA Porrúa, 2016.

Narro Robles, José. “Universidad con compromiso social”. ¿Hacia dónde va la universidad en el siglo XXI? Muñoz García, Humberto, coordinador. México: UNAM/MAPorrúa, 2016. 19-29.

Nussbaum, Martha. Crear capacidades: propuesta para el desarrollo humano. Barcelona: Paidós, 2012.

El cultivo de la humanidad: una defensa clásica de la reforma en la educación liberal. Barcelona: Herder, 2005.

Sin fines de lucro. Por qué la democracia necesita de las humanidades. Buenos Aires: Katz, 2012.

"El duro discurso de Martha Nussbaum sobre el futuro de la educación mundial", Analectapolit 6/10 (2016). Colgado en la red por el parque de ciencia y tecnología Explora, de Medellín, 167-178. Discurso pronunciado el 10 de diciembre con motivo del Doctorado Honoris Causa otorgado por la Universidad de Antioquia, Medellin, Colombia. DOI: http:// de.doi.org/10.18566/apolit.v6n10,a09

Picos B., Rolando. "La filosofía y las humanidades ante el nuevo ethos universitario". Los bordes de la filosofía. Educación, humani- 
dades y universidad. Xolocotzi, Ángel y Mateos, José Antonio, coordinadores. México: BUAP/Itaca, 2013. 215-226.

Revueltas, José. "Autogestión académica y universidad crítica", $O S A L$ IX/24 (2008): 154-159.

Sen, A. y Nussbaum, M. La calidad de vida, México: F.C.E., 1993.

Suárez Z. María Herlinda. "En defensa de la universidad pública". ¿Hacia dónde va la universidad en el siglo XXI? Muñoz García, Humberto, coordinador. México: UNAM/MPorrúa, 2016. 241-249.

Vergara Garay, Felipe. "Dilemas de la universidad actual: negocio o servicio". Los bordes de la filosofía. Educación, humanidades y universidad. Xolocotzi, Ángel y Mateos, José Antonio, coordinadores. México: BUAP/Itaca, 2013. 239-250.

Xolocotzi, Ángel y Mateos, José Antonio. Los bordes de la filosofía. Educación, humanidades y universidad. Coordinadores. México: BUAP/Itaca, 2013. 